\title{
Positive correlation of employment and psychological well-being for veterans with major abdominal surgery
}

\author{
David J. Horner, B.S., Christopher S. Wendel, M.S., Raymond Skeps, M.S., \\ Susan M. Rawl, Ph.D., Marcia Grant, D.N.Sc., C. Max Schmidt, M.D., \\ Clifford Y. Ko, M.D., Robert S. Krouse, M.D.*
}

Southem Arizona Veterans Affairs Health Care System, Surgical Care Line, 2-112, 3601 S. Sixth Ave., Tucson, AZ 85723, USA

\section{KEYWORDS: \\ Ostomy; \\ Quality of life; \\ Employment; \\ Psychological; \\ Veterans}

\begin{abstract}
BACKGROUND: Intestinal stomas (ostomies) have been associated negatively with multiple aspects of health-related quality of life. This article examines the relationship between employment status and psychological well-being (PWB) in veterans who underwent major bowel procedures with or without ostomy.

METHODS: Veterans from 3 Veterans Affairs (VA) medical centers were surveyed using the City of Hope ostomy-specific questionnaire and the Short Form 36 item Veteran's version (SF-36V). Response rate was $48 \%$ (511 of 1,063). Employment and PWB relationship was assessed using multiple regression with age, income, SF-36V physical component summary (PCS), and employment status as independent variables.

RESULTS: Employed veterans reported higher PWB compared with unemployed veterans $(P=$ .003). Full-time workers also reported higher PWB than part-time or unemployed workers $(P=.001)$. Ostomy was not an independent predictor of PWB.

CONCLUSIONS: Employment among veterans after major abdominal surgery may have intrinsic value for PWB. Patients should be encouraged to return to work, or do volunteer work after recovery. Published by Elsevier Inc.
\end{abstract}

Many surgical procedures can affect health-related quality of life (HRQOL). One such procedure that can dramatically alter HRQOL is an intestinal stoma (ostomy). Our group has examined these relationships in the veteran pop-

The views expressed in this article are those of the authors and do not necessarily reflect the position or policy of the Department of Veterans Affairs. The funder had no role in the design and conduct of the study; collection, management, analysis, and interpretation of the data; preparation, review or approval of the manuscript.

Presented as an abstract at the Association of VA Surgeons Annual Meeting, May 9, 2010, Indianapolis, IN.

* Corresponding author: Tel.: +1-520-792-1450, ext. 16145; fax: +1520-629-4603.

E-mail address: robert.krouse@va.gov

Manuscript received May 14, 2010; revised manuscript July 7, 2010 ulation extensively. Problems related to ostomies include feelings of embarrassment, ${ }^{1}$ sexuality, ${ }^{2}$ coping, ${ }^{3}$ spirituality ${ }^{4}$ and overall HRQOL. ${ }^{5}$ We have shown factors that have major roles in HRQOL in this population of patients including ostomy-related complications, ${ }^{6}$ and difficulty paying for supplies. ${ }^{7}$ We also have found that comorbidities ${ }^{8}$ actually may have a larger role in HRQOL than having an ostomy. Clearly, there are multiple other factors that contribute to a patient's postoperative HRQOL. It is important to test for other factors that may impact HRQOL and whether these factors can be altered in a positive manner.

Employment status and its impact on HRQOL has been examined related to severe medical problems. It has been shown to be related independently to HRQOL in spinal cord 
injury patients, ${ }^{9}$ stem cell transplant patients, ${ }^{10}$ and renal transplant survivors. ${ }^{11}$ It also has been shown to be independent of income in tetraplegia patients. ${ }^{9}$ In older adults, being employed may lead to fewer physician visits. ${ }^{12} \mathrm{We}$ have not encountered published research examining the relationship between employment and HRQOL in the ostomy population. The purpose of this study was to examine whether employment has a positive association with HRQOL, including physical well-being (PWB), independent of income, physical health, or age, that potentially can benefit veterans recovering from abdominal surgery.

\section{Methods}

An in-depth description of the methods design of the VA Ostomy HRQOL Study has been published elsewhere. ${ }^{13}$ Briefly, all subjects were veterans receiving care at VA Medical Centers in Tucson, Indianapolis, or Los Angeles. Subjects included 239 patients with known intestinal stomas (cases) and 272 patients who had similar procedures that did not lead to an ostomy (controls). ${ }^{5}$ Patients who underwent ostomy take-down were excluded. Patients were mailed the Short Form 36 item Veteran's version (SF-36V), a measure of general HRQOL adapted for use in veteran populations ${ }^{14-16}$ from the widely used Medical Outcomes Study Short Form (SF-36), ${ }^{17}$ and the modified City of Hope Quality of Life - Ostomy (mCOH-QOL-O) questionnaire. ${ }^{18}$

The SF-36V retains the original SF-36 measurement model, which includes 8 multi-item scales (ie, physical function, role limitations owing to physical problems, bodily pain, general health perceptions, vitality, social functioning, role limitations owing to emotional problems, and mental health) as well as physical component summary (PCS) and mental component summary scores. The subscales and component summary scores have a possible range of 0 to 100 , with higher scores reflecting better functioning and/or well-being. ${ }^{8}$

The PI and investigators from the City of Hope developed and tested the mCOH-QOL-O questionnaire. It is based on a 4-dimensional framework consisting of ostomyrelated HRQOL (physical, psychological, social, and spiritual well being). A score for total HRQOL, as well as the 4 domains, is calculated as the average of relevant groups of linear analogue questions with response options on a scale from 0 to 10 , with higher scores reflecting higher levels of well-being. ${ }^{13}$

Psychometric testing was performed with 1,513 ostomates, including cancer and noncancer populations. Factor analysis revealed 4 factors parallel to the 4 dimensions of the model. Reliability testing using the Cronbach $\alpha$ coefficient revealed an overall $\alpha$ value of .95, with the dimension subscales ranging from .77 to .90 . Validity testing included content, construct, discriminant, and criterion-related approaches. ${ }^{18}$

Scales were scored and missing data were handled according to the instrument developers' scoring algorithms.
The SF-36V scale scores were coded as missing if more than half of the responses for the scale's items were missing. Each participant signed an Institutional Review Board-approved written informed consent form.

\section{Data analysis}

The chi-square test and the Student $t$ test were used in exploratory analysis to observe how averaged responses to HRQOL survey questions varied according to work status: full-time, part-time, retired, or not working. However, to ultimately determine if employment has a direct independent association with HRQOL, a multiple regression model was created for each mCOH-QOL-O domain scale that incorporated independent variables that were correlated with employment or HRQOL in bivariate analyses of the previously mentioned studies, which possibly could confound the apparent relationship between the 2 in this study. Therefore, independent variables of age, income, a PCS scale of physical health from the SF-36V, and employment were placed into the models. Other clinical and demographic factors, such as having an ostomy, were evaluated as independent predictors in the models. The regression models used as end points the overall summary score and scores for each of the 4 domains of the $\mathrm{mCOH}-\mathrm{QOL}-\mathrm{O}$ for cases and controls: PWB, social well-being, spiritual wellbeing, and physical well-being. Both the independent variables of age and PCS were continuous variables. Income was dichotomized to reflect annual household income; greater than or less than $\$ 30,000$ was used because it was the closest to the median income of our patients. Patients were considered employed if they reported working part time or full time whether they were retired or not. A second model for each end point tested working full time compared with part-time work or unemployed. To observe how retirement influences the outcome in these models they were calculated twice, first excluding responses of retired patients from veterans who were unemployed (model 1) or were not working full time (model 2). Then, the regression models were calculated while including responses from retired patients with veterans who were unemployed (model 1) or not working full time (model 2).

Model 1: HRQOL scale $=\beta_{\text {income }}+\beta_{\mathrm{PCS}}+\beta_{\text {age }}+\beta_{\text {employment }}$
Model 2: HRQOL scale $=\beta_{\text {income }}+\beta_{\mathrm{PCS}}+\beta_{\text {age }}+\beta_{\text {full time }}$

\section{Results}

\section{Demographics by employment status}

Table 1 compares factors associated with work status between employed and unemployed veterans, veterans who are working full-time versus veterans who are working part time or unemployed, and retired veterans versus veterans 
Table 1 Demographics of veterans with major abdominal surgery by work status

\begin{tabular}{|c|c|c|c|c|c|}
\hline & $\begin{array}{l}\text { Employed } \\
(n=107)\end{array}$ & $\begin{array}{l}\text { Unemployed } \\
(n=60)\end{array}$ & $\begin{array}{l}\text { Full time } \\
(n=66)\end{array}$ & $\begin{array}{l}\text { Not full time } \\
(n=101)\end{array}$ & $\begin{array}{l}\text { Retired } \\
(n=328)\end{array}$ \\
\hline Average age, $y$ & $62(S D, 11.5)$ & $59(S D, 11.8)$ & $59(\mathrm{SD}, 11.7)$ & $61(\mathrm{SD}, 12.3)$ & $72(S D, 10.2)$ * \\
\hline Average PCS out of 100 & $43(S D, 9.1)^{f}$ & $32(S D, 9.9)^{f}$ & $45(S D, 8.4)^{f}$ & $34(S D, 10.2)^{\ddagger}$ & 35 (SD, 10.4) \\
\hline$\%$ Male & 95 & 95 & 94 & 96 & 95. \\
\hline$\%$ Partnered & 56 & 45 & 56 & 47 & $60^{5}$ \\
\hline$\%$ High school graduate & 71 & 57 & 76 & 62 & $53^{5}$ \\
\hline $\begin{array}{l}\% \text { Annual household income }>\$ 30,000 \\
\text { Race }\end{array}$ & $44^{\dagger}$ & $19^{t}$ & $61^{\ddagger}$ & $19^{\ddagger}$ & 22 \\
\hline$\%$ Non-Hispanic white & 84 & 72 & 82 & 76 & 82 \\
\hline$\%$ Hispanic & 6 & 13 & 8 & 9 & 6 \\
\hline$\%$ African American & 6 & 13 & 8 & 11 & 9 \\
\hline$\%$ Other/unknown & 4 & 2 & 2 & 4 & 3 \\
\hline \multicolumn{6}{|l|}{ Reason for surgery } \\
\hline$\%$ Colorectal cancer & 39 & 43 & 32 & 40 & 52 \\
\hline$\%$ Benign tumor & 9 & 5 & 7 & 8 & 10 \\
\hline$\%$ Inflammatory disease & 24 & 11 & 29 & 13 & 11 \\
\hline$\%$ Acute inflammation/ infection & 14 & 21 & 12 & 22 & 15 \\
\hline$\%$ Other & 14 & 20 & 20 & 17 & 12 \\
\hline$\%$ Ostomy & 39 & 48 & 36 & 46 & 48 \\
\hline$\%$ Permanent ostomy & 87 & 82 & 87 & 82 & 87 \\
\hline $\begin{array}{l}S D=\text { standard deviation; } P C S=\text { physical } \\
{ }^{*} P \text { value } \leq .001 \text { (retired vs not retired). } \\
\dagger P \text { value } \leq .001 \text { (employed vs unemploye } \\
\$ P \text { value } \leq .001 \text { (full-time vs not full-tim } \\
\S P \text { value } \leq .05 \text { (retired vs not retired). }\end{array}$ & onent summe & & & & \\
\hline
\end{tabular}

who are not retired. The average PCS score was associated highly with work status. The PCS for employed patients (43 of 100 ) was more than 1 standard deviation above the PCS for unemployed patients (32 of 100) and the PCS for fulltime patients (45 of 100) was also more than 1 standard deviation above the PCS for patients not working full time. These associations remained when retired patients were included with those who were unemployed or not employed full time, even though PCS was not associated with retirement. Income was associated significantly with employment $(P \leq .001)$. The percentage of employed patients with a household income greater than $\$ 30,000$ (44\%) was more than double the percentage of unemployed patients $(19 \%)$, and the percentage of patients working full time making more than $\$ 30,000$ (61\%) was more than triple the percentage of patients not working full time $(19 \%)$. These associations were still significant after retired patients were included in the analysis. Retired patients had a slightly lower annual income than patients who were not retired, but the difference was not significant.

The average age of patients of different work status was approximately the same (range 59-62) and the standard deviation was equivalent. Age was associated significantly with retirement $(P<.0001)$, but not quite significant for employment $(P=.059)$. Patients were predominantly male (range 94\%-96\%). Both age and sex were not associated with employment. A patient's marital/partner status was not associated with employment, however, it was associated significantly with retired patients $(P=.021)$. Graduation from high school also was associated with retirement $(P=$
$.009)$ and with any employment $(P=.002)$ or full-time work status $(P=.002)$ if retired patients were included. When retired patients were excluded from analysis high school graduation was not below the $\alpha$ threshold to be considered significant ( $P=.06$ and $P=.079$, respectively).

Patients in our analysis were predominantly non-Hispanic whites, followed by Hispanics and African Americans. There was a slight increase in non-Hispanic whites among working patients and a slight increase in minorities among unemployed patients, but these differences were not significant.

Colorectal cancer was the most common reason for surgery and benign tumor was the least common, regardless of work status. Inflammatory disease, acute inflammation/infection, and other causes decreased between these 2 . The reason for surgery was not associated with work status when retired patients were excluded from analysis; however, when responses from retired veterans were included in the analysis the reason for surgery was associated with all employment $(P=.008)$ and strictly full-time employment $(P=.001)$. Whether patients received an ostomy as part of their treatment was not associated with employment, duration of the ostomy was not associated either (temporary vs permanent).

\section{Regression models}

Employment status was not associated significantly with physical, social, or spiritual well-being, but it was associated with PWB. The first regression model compared em- 
Table 2 Linear regression model fitted by psychological quality of life among those employed

Retired excluded employed $(n=107)$

Retired included employed $(n=107)$

unemployed $(n=60)$

\begin{tabular}{|c|c|c|c|c|c|c|}
\hline Explanatory variables & B coefficients & $95 \% \mathrm{CI}$ & $P$ value & B coefficients & $95 \% \mathrm{CI}$ & $P$ value \\
\hline $\begin{array}{l}\text { Income }>\$ 30,000 \\
\text { SF36V PCS }\end{array}$ & $\begin{array}{l}.67 \\
.084\end{array}$ & $\begin{array}{r}.12-1.2 \\
.057-.11\end{array}$ & $\begin{array}{c}.017 \\
<.0001\end{array}$ & $\begin{array}{l}.46 \\
.080\end{array}$ & $\begin{array}{l}.082-.84 \\
.063-.096\end{array}$ & $\begin{array}{c}.017 \\
<.0001\end{array}$ \\
\hline Age & .048 & $.025-.071$ & $<.0001$ & .054 & $.040-.069$ & $<.0001$ \\
\hline Employed & .97 & $.33-1.6$ & .003 & .52 & $.093-.96$ & .017 \\
\hline
\end{tabular}

CI = confidence interval; PCS = physical component summary.

ployed veterans (part time or full time) with veterans who were not employed and not retired. Independent variables, income, PCS, age, and employment were all associated significantly with PWB. Employed veterans had a higher PWB than unemployed veterans by 1 point on an 11-point scale $(P=.003)$. This is shown in Table 2 . When this same model included responses from retired veterans among those who were not employed these same independent variables still were shown to be associated significantly with PWB. The coefficient for employment decreased to .52 , but still was significant (shown in Table 2).

The second regression model compared veterans who worked full time with those who were not working full time (not employed or only working part time) and not retired. In this model the independent variables PCS, age, and fulltime work status were all associated significantly with PWB even though income was not shown to be a significant factor. Full-time workers had a higher PWB than veterans who did not work full time by 1.1 points on an 11-point scale $(P=.024)$ (Table 3$)$. When the second model included retired individuals among those who were not working full time the variables of income, PCS, age, and fulltime work status were all significant factors of PWB (Table 3). The coefficient for employment decreased to .61, but was still significant (Table 3). The variables of age, PCS, and full-time work status, but not income, were also associated significantly with the total HRQOL in veterans (not shown). Having an ostomy was not an independent predictor of PWB when included in either regression model. Inclusion of an interaction term between employment and emergent versus elective surgery indicated that emergent surgery did not modify the association between PWB and employment significantly $(P=.17)$.

\section{Comments}

The main conclusion of this study was that being employed is associated with higher PWB in veterans who have undergone major abdominal surgery independent of age, income, or physical health. This verification is substantial because age and physical health and income are all highly correlated with PWB. This runs counter to the notion that employed veterans report a higher PWB than unemployed veterans because they are more healthy than unemployed veterans. A partial explanation may be that the work environment and activities may provide some stability to veterans who are subject to the vicissitudes created by disease and also may prevent patients from becoming overly preoccupied with their illness. The finding that employment is associated with an increased PWB independent of household income indicates that employment has intrinsic value and benefits patients beyond monetary compensation alone, especially because the number of employed patients with an annual income of more than $\$ 30,000$ was more than double the number of unemployed patients with that same income, and there were 3 times as many patients who made more than $\$ 30,000$ than those who did not. These findings show that there are more benefits of working than only financial security. Having an occupation may increase one's sense of self-confidence, purpose, and utility in society.

Table 3 Linear regression model fitted by psychological quality of life among those employed full-time

\begin{tabular}{|c|c|c|c|c|c|c|}
\hline \multirow[b]{2}{*}{ Explanatory variables } & \multicolumn{3}{|c|}{$\begin{array}{l}\text { Retired excluded full-time }(n=66) \\
\text { not full-time }(n=101)\end{array}$} & \multicolumn{3}{|c|}{$\begin{array}{l}\text { Retired included full-time }(n=66) \\
\text { not full-time }(n=385)\end{array}$} \\
\hline & B coefficients & $95 \% \mathrm{CI}$ & $P$ value & B coefficients & $95 \% \mathrm{CI}$ & $P$ value \\
\hline $\begin{array}{l}\text { Income }>\$ 30,000 \\
\text { SF36V PCS } \\
\text { Age } \\
\text { Employed full time }\end{array}$ & $\begin{array}{l}.44 \\
.081 \\
.045 \\
1.1\end{array}$ & $\begin{array}{c}-.17 \text { to } 1.1 \\
.052-.11 \\
.023-.068 \\
.44-1.8\end{array}$ & $\begin{array}{c}.152 \\
<.0001 \\
<.0001 \\
.001\end{array}$ & $\begin{array}{l}.40 \\
.081 \\
.051 \\
.61\end{array}$ & $\begin{array}{l}.013-.79 \\
.065-.097 \\
.037-.066 \\
.079-1.1\end{array}$ & $\begin{array}{c}.043 \\
<.0001 \\
<.0001 \\
.024\end{array}$ \\
\hline
\end{tabular}


The average age of patients in this study was almost double that of the general US population (average age, $35 \mathrm{y}$ ), ${ }^{19}$ but approximately the same as the veteran population that has been treated with major abdominal surgery. Therefore, although these data may have broader implications to the general population, they have a specific application to the veteran population. The increased average age may explain why age was only significantly associated with employment when retired patients were included in the analysis.

Preliminary data on work status showed that the highest scores on individual survey questions were from full-time workers, followed by part-time workers, followed by retired veterans, and the lowest were from those who did not work at all. The finding that full-time workers have a higher PWB than veterans who do not work full-time is important because even though the number of observations of full-time workers $(n=66)$ is more than one-third less than observations of total workers $(n=107)$ it is still statistically significant $(P=.001)$. Also, this second regression model did not just compane full-time workers with unemployed, but instead compared them with those who are unemployed or working part time. This reinforces the hypothesis that veterans who work full time have a higher PWB than veterans who work part time, and that veterans who work part time have a higher PWB than veterans who are unemployed.

The majority of individuals who are retired are no longer working because they have retired. These patients are in a different set of circumstances than patients who classically are considered unemployed; not working and not retired. These patients have many different concerns that contribute to PWB than the retired patient. Therefore, both regression models were examined, first with the unemployed/not working full-time patients who also were not retired, then, afterward, including the retired patents. The fact that work status had a significant positive association with PWB even after including responses from retired patients in the analysis further strengthens the argument that employment has intrinsic worth and potential to benefit the lives of our patients after recovering from a major surgery.

Although ostomy status was not a predictor of PWB, ostomates and controls were represented equally in this study sample, indicating that both groups can benefit from returning to work after their surgery.

As an exploratory analysis of a larger study that was designed to observe the effects of global issues on the total HRQOL of veterans with ostomies, the current analysis had some limitations in detailing the effects of employment on PWB. For example, this analysis allowed us to conclude that having a job has a positive association with PWB, but it did not allow for observation of attitudes toward employment, social interaction, satisfaction of accomplishment, and attainment of knowledge or work skills associated with a particular vocation. Future studies should examine specific attitudes toward one's occupation. In addition, prospective evaluations of the benefit of employment, including volunteer service and charity work, could help to further elucidate the holistic value of being employed or working in general.

\section{Acknowledgments}

This work originated with the Research Service Line at the Southern Arizona VA Health Care System in Tucson, AZ, and was supported by grant IIR 02-221 from the Veterans Affairs Health Services Research and Development Service and a National Institutes of Health research training grant (T35HL 007479), Short-Term Training: Students in Health Professional Schools. Resources and facilities were provided at the Southern Arizona VA Health Care System (Tucson, AZ).

\section{References}

1. Mitchell KA, Rawl SM, Schmidt CM, et al. Demographic, clinical, and quality of life variables related to embarrassment in veterans living with an intestinal stoma. J Wound Ostomy Continence Nurs 2007;34: 524-32.

2. Symms MR, Rawl SM, Grant M, et al. Sexual health and quality of life among male veterans with intestinal ostomies. Clin Nurs Spec 2008 22:30-40.

3. Krouse RS, Grant M, Rawl SM, et al. Coping and acceptance: the greatest challenge for veterans with intestinal stomas. J Psychosom Res 2009;66:227-33.

4. Baldwin CM, Grant $\mathbf{M}$, Wendel $\mathbf{C}$, et al. Influence of intestinal stoma on spiritual quality of life of U.S. veterans. J Holist Nurs 2008;26: 185-94.

5. Krouse RS, Grant M, Wendel CS, et al. A mixed-methods evaluation of health-related quality of life for male veterans with and without intestinal stomas. Dis Colon Rectum 2007;50:2054-66.

6. Pittman J, Rawl S, Grant M, et al. Demographic and clinical factors related to ostomy complications and quality of life in veterans with an ostomy. J Wound Ostomy Continence Nurs 2008;35:493-503.

7. Coons SJ, Chongpison Y, Wendel CS, et al. Overall quality of life and difficulty paying for ostomy supplies in the Veterans Affairs ostomy health-related quality of life study: an exploratory analysis. Med Care 2007; 45:891-5.

8. Jain S, McGory ML, Ko CY, et al. Comorbidities play a larger role in predicting quality of life compared to having an ostomy. Am J Surg 2007;194:774-9.

9. Anderson CJ, Krajci KA, Vogel LC. Life satisfaction in adults with pediatric-onset spinal cord injuries. J Spinal Cord Med 2002;25:184-90.

10. Bieri S, Roosnek E, Helg C, et al. Quality of life and social integration after allogeneic hematopoietic SCT. Bone Marrow Transplant 2008; 42:819-27.

11. Chen WC, Chen CH, Lee PC, et al. Quality of life, symptom distress, and social support among renal transplant recipients in Southern Taiwan: a correlational study. J Nurs Res 2007;15:319-29.

12. Tokuda $Y$, Ohde S, Takahashi $O$, et al. Relationships between working status and health or health-care utilization among Japanese elderly. Geriatr Gerontol Int 2008;8:32-40.

13. Krouse RS, Mohler MJ, Wendel CS, et al. The VA ostomy healthrelated quality of life study: objectives, methods, and patient sample. Curr Med Res Opin 2006;22:781-91.

14. Kazis LE, Miller DR, Clark J, et al. Health-related quality of life in patients served by the Department of Veterans Affairs: results from the Veterans Health Study. Arch Intern Med 1998;158:626-32.

15. Kazis LE, Ren XS, Lee A, et al. Health status in VA patients: results from the Veterans Health Study. Am I Med Qual 1999;14: $28-38$. 
16. City of Hope/Beckman Research Institute Pain Resource Center Research Instruments. Available at: http:/www.cityofhope.org/prc/pdf/ Quality\%20of\%20Life\%200stomy.pdf. Accessed: May 11, 2010.

17. Ware JE Jr, Sherbourne CD. The MOS 36-item short-form health survey (SF-36). I. Conceptual framework and item selection. Med Care 1992;30:473-83.
18. Grant M, Ferrell B, Dean D, et al. Revision and psychometric testing of the City of Hope quality of life-ostomy questionnaire. Qual Life Res 2004;13:1445-57.

19. Meyer J. Age: 2000. U.S. Census Bureau census 2000 brief, issued October 2001. Available at: http:/www.census.gov/prod/2001pubs/ c2kbr01-12.pdf. Accessed: May 11, 2010. 